\title{
Atmospheric Remnants in the Low Earth Orbit Region around 200 km Altitude
}

\author{
Konstantinos Katsonis', Chloe Berenguer'1, José Gonzalez del Amo², \\ Constantinos Stavrinidis ${ }^{2}$ \\ ${ }^{1}$ DEDALOS Ltd., Thessaloniki, Greece \\ ${ }^{2}$ ESTEC, European Space Agency, Noordwijk, The Netherlands \\ Email: katsonis.dedalos@gmail.com
}

Received 5 June 2015; accepted 15 October 2015; published 22 October 2015

\begin{abstract}
Study of atmospheric remnants in the low Earth orbit region ( $200 \mathrm{~km}$ altitude) using Global Models, with application to electric thrusters of in situ resources utilization type.
\end{abstract}

\section{Keywords}

Atmospheric Composition, Low Earth Orbit, Air-Breathing, Global Modeling

\section{Introduction}

Knowledge of the Earth Atmospheric Remnants (AtR) composition at altitudes from $180 \mathrm{~km}$ to $240 \mathrm{~km}$ is of paramount importance for the development of air-breathing technology which is of interest here, mainly addressing needs of Low Earth Orbits (LEO). Hall Effect Thruster (HET) and Radio-frequency Ionization Thruster (RIT) devices are expected to be used in this case. More generally, atmosphere composition is also important for satellite drag and re-entry studies.

The altitudes we are interested in belong to the thermosphere part of the atmosphere. A considerable number of studies has been made on the thermosphere composition. A general introduction on the subject, including an extended references list, can be found in [1]. In a general way, the thermosphere exhibits high temperatures (say from $600 \mathrm{~K}$ to $1400 \mathrm{~K}$ ) and quite low pressures, of about $10^{-9} \mathrm{~Pa}$ at $200 \mathrm{~km}$ altitude. Ultra Violet (UV) solar radiation constitutes the main contributor to the thermosphere heating. Under the influence of the Earth magnetic field most of the charged particles coming from the Sun are deflected, but a considerable fraction of them still enters in the polar regions. As far as UV solar radiation is concerned, activity cycles are observed which last about 11 years. Moreover, the Earth magnetic field is subject to sudden geomagnetic storms, which are shortlived events. Both of these phenomena result to big variations. Additionally, diurnal and seasonal variations are observed depending on the Sun-Earth geometry, set aside semi-annual variations of which the origin is unclear. The aforementioned Solar and Geomagnetic (S \& G) activities, have a direct influence on the temperature in the thermosphere and consequently on the present species total densities and compositions.

Important experiments have been realized and adequate models developed to study and to characterize the thermosphere, beginning at the end of the last century. These are briefly addressed in the following Section 2. Main compendia of recommended data concerning the thermosphere are discussed in Section 3. These include 
results coming from DEDALOS Ltd. code 4CGM. Global Model (GM) support of air-breathing technology is addressed in Section 4. Conclusions are given in Section 5.

\section{Short Literature Overview}

The main approach of the thermosphere study consists in empirical modeling. An extensive description of the subject can be found in Chap. 2 of [1]. As reported there, three main types of empirical models exist, allowing for description of the thermosphere composition:

$\alpha$ The Jacchia type models, using observations of orbital motions of satellites under the influence of drag. Recently, Jacchia-Bowel (JB) improved codes were developed by US Air Force including additional variations and activity data. On this subject, see [2] and references therein for JB2006 version and [3] for JB2008 one.

$\beta$ Density effects on Drag and Temperature Models (DTM), based on observation of satellite drag results and temperature of the neutral atmosphere. However, they use a more generalized model formulation, see [4] for DTM-2000 and [5] for DTM-2009.

$\gamma$ Mass Spectrometer and Incoherent Scatter Extended (MSISE) models, initially based solely on mass spectrometer and incoherent scatter radar observations. The two most recent versions of such models are:

- MSISE-90 code, see [6]. Results were included in the European standard of year 2000 (ECSS-04A, [7]) and used in the air-breathing study of Di Cara et al. [8].

- NRL-MSISE-00 code, now developed by Naval Research Laboratory, see [9]. Results were included in the European standard of year 2008 (ECSS-04C, [10]) and in the standard ISO [11]. Their values have been repeated partially in Shabshelowitz thesis [12].

The same parameters which are used in the MSISE codes are also used for HWM models for the horizontal wind evaluation. Wind influence is not addressed here, as it is not so important in our case.

The European Standard of 2000, [7] had recommended to use the code $\gamma$ MSISE-90 for the total density of species, for the composition of the components and for the temperature of the neutrals, while the European Standard of 2008, [10] recommends to use the code $\alpha$ Jacchia JB2006 for the total density of species and the code $\gamma$ NRL-MSISE-00 for the composition of the components and for the neutral temperature. Note that the International Standard of 2011, [11] recommends to use the code $\alpha$ Jacchia JB2008 for the total density of species and the same code $\gamma$ NRL-MSISE-00 for the composition of the components and for the temperature of the neutrals.

Empirical models have been reported to be in agreement with the available experimental results even if some discrepancies exist [5]. Experiments include mainly satellite observations. The CHAMP (250 km - $450 \mathrm{~km})$, GRACE (430 km - $490 \mathrm{~km})$ and GOCE (255 km) accelerometer measurement devices [1] as well as the DORIS and SLR tracking data devices embarked on-board satellites have given widely used results [13] [14]. Groundbased Fabry-Perot Interferometers (FPI) are also used giving information near $250 \mathrm{~km}$, but they give results with limited horizontal resolution and vertical coverage for higher thermosphere [14]. Temperature is often measured using emission from molecular $\mathrm{O}_{2}$ (A band) and the $630 \mathrm{~nm}$ line of atomic oxygen for lower and higher thermosphere respectively [14]. This corresponds to the expected $\mathrm{O}_{2} / \mathrm{O}$ amounts present at these altitudes.

Measurements of the Sun radiations are recorded on ground in various observatories around the Earth and are combined to make global data in "near-real time". Those data may be included in various empirical models to obtain better results. Moreover, density observations derived from satellite dynamics can contribute to the empirical density models. This procedure is known as "model calibration". Such implementation and calibration techniques were developed recently in the frame of ESA contracts, see [1] [15]-[17].

In addition to the three types of models mentioned previously, we mention:

$\delta$ Models based on calibrations techniques, as is the case of the Near-Real Time Calibration Model (NRTCM) funded by ESA, developed by Doornbos. This model had already adjusted the NRL-MSISE-00 model to reduce the model error up to 30\%, [13]. Two ESOC and an ESTEC contracts addressed calibration models proposed by Doornbos, [15]-[17].

$\varepsilon$ The 4CGM, a Four Components Global Model type code [18], especially addressing here altitudes of about $180 \mathrm{~km}$ to $240 \mathrm{~km}$. The use of 4CGM in the atmospheric context, first introduced in [19], is described in the dedicated Section 4, see also [20]. The four components taken initially into consideration, $\mathrm{O} / \mathrm{O}_{2}$ and $\mathrm{N} / \mathrm{N}_{2}$, are the most present species in the aforementioned altitudes region.

The main parameters of interest here are temperature $\left(\mathrm{T}_{\mathrm{GAS}}\right)$, mass $(\rho)$ and number $(n)$ densities and pressure 
$(p)$. Composition of the thermosphere and percentages of the four main constituents $\left(\mathrm{O}, \mathrm{O}_{2}, \mathrm{~N}, \mathrm{~N}_{2}\right)$ are investigated elsewhere [21]. Typical numerical results obtained by 4CGM are given in Table 1 "Selected 4CGM numerical results". Data in this table appear separately following each of the four figures which are shown and commented in Section 3. The four rows belonging to each kind of S\&G activities (low, mean, high and very high) pertain to $180 \mathrm{~km}, 200 \mathrm{~km}, 220 \mathrm{~km}$ and $240 \mathrm{~km}$ altitudes successively. Results of this code and detailed discussion including comparison with data available in the literature will be made available elsewhere.

\section{Components Composition from MSISE Codes}

Variations of the thermosphere composition as a function of the altitude from $180 \mathrm{~km}$ up to $240 \mathrm{~km}$ for low S \& $\mathrm{G}$ activities are illustrated in Figure 1. It includes results from NRL-MSISE-00 (plain lines with symbols) and those of MSISE-90 (dashed lines). Atomic oxygen $\mathrm{O}$ (red lines), $\mathrm{N}_{2}$ (blue lines), $\mathrm{O}_{2}$ (red lines), $\mathrm{N}$ (blue lines), He (black lines), Ar (green lines) and $\mathrm{H}$ species (orange lines) are included. Also, total density is represented by a magenta line. The total density is calculated by us, summing the densities of the main seven species as they are given in the literature. We observe in Figure $\mathbf{1}$ that the most abundant species is $\mathrm{O}$, followed by $\mathrm{N}_{2}$ for all the

Table 1. Selected 4 CGM numerical results.

\begin{tabular}{|c|c|c|c|c|}
\hline \multicolumn{5}{|c|}{ Low S \& G activities (see Figure 1) } \\
\hline $\mathrm{n}_{\mathrm{O}}$ & $\mathrm{n}_{\mathrm{N} 2}$ & $\mathrm{n}_{\mathrm{O} 2}$ & $\mathrm{n}_{\mathrm{N}}$ & $\mathrm{n}_{\mathrm{TOT}}$ \\
\hline 4.93E9 & $4.75 \mathrm{E} 9$ & 3.72E8 & $2.81 \mathrm{E} 7$ & $1.01 \mathrm{E} 10$ \\
\hline 2.73E9 & $1.80 \mathrm{E} 9$ & $1.28 \mathrm{E} 8$ & $2.11 \mathrm{E} 7$ & 4.70E9 \\
\hline $1.60 \mathrm{E} 9$ & 7.17E8 & 4.35E7 & $1.52 \mathrm{E} 7$ & $2.38 \mathrm{E} 9$ \\
\hline 9.43E8 & 2.93E8 & 1.61E7 & $1.08 \mathrm{E} 7$ & $1.26 \mathrm{E} 9$ \\
\hline \multicolumn{5}{|c|}{ Mean S \& G activities (see Figure 2) } \\
\hline $\mathrm{n}_{\mathrm{O}}$ & $\mathrm{n}_{\mathrm{N} 2}$ & $\mathrm{n}_{\mathrm{O} 2}$ & $\mathrm{n}_{\mathrm{N}}$ & $\mathrm{n}_{\mathrm{TOT}}$ \\
\hline 7.24E9 & $7.01 \mathrm{E} 9$ & 4.15E8 & $5.04 \mathrm{E} 7$ & $1.47 \mathrm{E} 10$ \\
\hline 4.66E9 & $3.29 \mathrm{E} 9$ & 1.67E8 & $4.54 \mathrm{E} 7$ & 8.16E9 \\
\hline 3.05E9 & $1.62 \mathrm{E} 9$ & $7.14 \mathrm{E} 7$ & 4.03E7 & 4.78E9 \\
\hline $2.08 \mathrm{E} 9$ & 8.37E8 & $3.28 \mathrm{E} 7$ & $3.08 \mathrm{E} 7$ & $2.98 \mathrm{E} 9$ \\
\hline \multicolumn{5}{|c|}{ High S \& G activities (see Figure 3) } \\
\hline $\mathrm{n}_{\mathrm{O}}$ & $\mathrm{n}_{\mathrm{N} 2}$ & $\mathrm{n}_{\mathrm{O} 2}$ & $\mathrm{n}_{\mathrm{N}}$ & $\mathrm{n}_{\mathrm{TOT}}$ \\
\hline $1.13 \mathrm{E} 10$ & $1.02 \mathrm{E} 10$ & 4.82E8 & $1.21 \mathrm{E} 8$ & $2.21 \mathrm{E} 10$ \\
\hline 7.61E9 & $5.27 \mathrm{E} 9$ & $1.98 \mathrm{E} 8$ & $1.29 \mathrm{E} 8$ & $1.32 \mathrm{E} 10$ \\
\hline 5.37E9 & 2.93E9 & $1.00 \mathrm{E} 8$ & $1.15 \mathrm{E} 8$ & $8.52 \mathrm{E} 9$ \\
\hline 3.94E9 & 1.73E9 & $4.94 \mathrm{E} 7$ & $9.49 \mathrm{E} 7$ & $5.81 \mathrm{E} 9$ \\
\hline \multicolumn{5}{|c|}{ Very high S \& G activities (see Figure 4) } \\
\hline $\mathrm{n}_{\mathrm{O}}$ & $\mathrm{n}_{\mathrm{N} 2}$ & $\mathrm{n}_{\mathrm{O} 2}$ & $\mathrm{n}_{\mathrm{N}}$ & $\mathrm{n}_{\mathrm{TOT}}$ \\
\hline $1.98 \mathrm{E} 10$ & $1.44 \mathrm{E} 10$ & $1.54 \mathrm{E} 9$ & $1.51 \mathrm{E} 9$ & $3.73 \mathrm{E} 10$ \\
\hline $1.44 \mathrm{E} 10$ & $8.44 \mathrm{E} 9$ & $8.21 \mathrm{E} 8$ & $1.12 \mathrm{E} 9$ & $2.48 \mathrm{E} 10$ \\
\hline $1.10 \mathrm{E} 10$ & 5.23E9 & $4.60 \mathrm{E} 8$ & 8.56E8 & $1.76 \mathrm{E} 10$ \\
\hline 8.47E9 & 3.38E9 & $2.74 \mathrm{E} 8$ & $6.76 \mathrm{E} 8$ & $1.28 \mathrm{E} 10$ \\
\hline
\end{tabular}




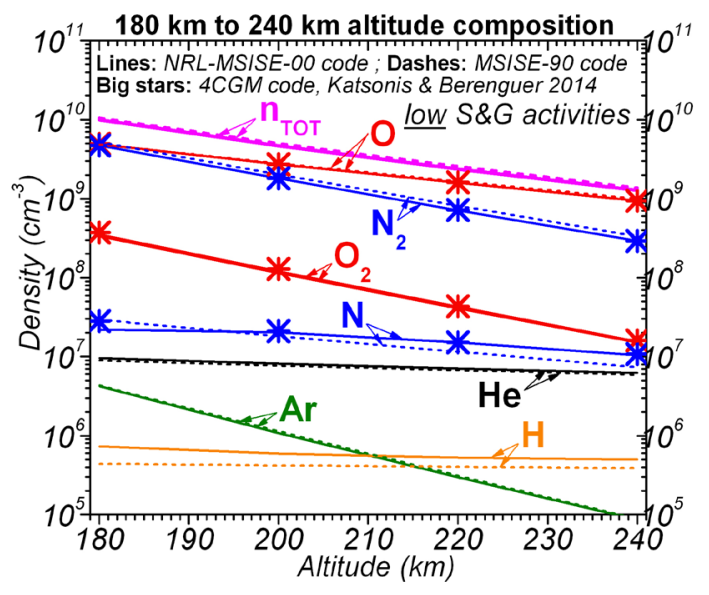

Figure 1. Comparison of species compositions for low activities.

altitudes represented, except that for $180 \mathrm{~km}$, where $\mathrm{O}$ density is the same than this of $\mathrm{N}_{2}$. The $\mathrm{O}_{2}$ density is between 1.5 and 2 orders of magnitude lower that this of $\mathrm{O}$, illustrating the important $\mathrm{O}_{2}$ dissociation. Atomic $\mathrm{N}$, the fourth component, shows a quite low density. According to results from the literature, presence of $\mathrm{He}, \mathrm{Ar}$ and $\mathrm{H}$ is also observed. In a general way, we see that heavier components $\left(\mathrm{N}_{2}, \mathrm{O}_{2}\right.$ and $\mathrm{Ar}$ ) are decreasing quickly with the altitude. Atomic oxygen and nitrogen $(\mathrm{O}, \mathrm{N})$ having lighter masses are decreasing in a slower way. Finally, densities of the lighter components $(\mathrm{H}, \mathrm{He})$ diminish very slowly with altitude. It is also to be noted that decrease rate of $\mathrm{N}$ is quite lower than this of $\mathrm{O}$, because $\mathrm{N}$ components are fed from $\mathrm{N}_{2}$ dissociation. The latter increase with altitude, leading to a somehow flat density curve for N. Results from the two MSISE codes compare quite well, except for $\mathrm{N}_{2}, \mathrm{~N}$ and $\mathrm{H}$, where substantial differences are observed. Our results from 4CGM, obtained when $\rho$ and $\mathrm{T}_{\mathrm{GAS}}$ are used as input, are also included in Figure 1 (big stars) pertaining to the four main components. These results are very close to those of NRL-MSISE-00 for $\mathrm{O}, \mathrm{N}_{2}$ and $\mathrm{O}_{2}$ species. However, we obtain a slightly smoother $\mathrm{N}$ density variation. Indeed, 4CGM calculations result to a $\mathrm{N}$ density slightly higher than this of NRL-MSISE-00 for $180 \mathrm{~km}$ altitude. Note that although input data used in the 4CGM calculations were in fact taken from NRL-MSISE-00, our results are in agreement with MSISE-90 results for $180 \mathrm{~km}$ altitude.

For mean $S \&$ G activity variations, density as a function of the altitude for the same seven species addressed previously, are illustrated in Figure 2. Results from NRL-MSISE-00 (plain lines) and those of MSISE-90 (dashed lines) are included in this figure. Also, the values read approximately from Figure 2 of [8] (thin lines with triangles) are represented. Moreover, we report results from our 4CGM (big stars) as was the case in the previous Figure 1. In the mean S \& G activities case, heavy species densities decrease quickly with altitude while light elements have quite constant densities, as was the case for low activity illustrated in Figure 1. We observe that the two versions of the MSISE code give very close results for $\mathrm{O}, \mathrm{N}_{2}$ (which are the prevailing species) and for $\mathrm{He}$ and $\mathrm{Ar}$, while for those for $\mathrm{O}_{2}, \mathrm{~N}$ and $\mathrm{H}$ species, densities present important differences. Especially, the $\mathrm{O}_{2}$ density is about $30 \%$ lower with the new code version NRL-MSISE-00 in comparison with MSISE-90. It is to be noted that our 4 CGM results give $\mathrm{O}_{2}$ densities located between those of NRL-MSISE-00, and those of MSISE-90. Moreover, the $\mathrm{N}$ density we calculate for $180 \mathrm{~km}$ altitude is slightly higher than this of NRL-MSISE-00, as was also the case in the previous Figure 1.

Variations of the density of species as a function of the altitude for high S \& G activity are illustrated in Figure 3. In this figure, results from NRL-MSISE-00 are represented (plain lines), together with results from our 4CGM (big stars). Here again, we observe that heavier species densities decrease quickly with altitude.

Lighter species have almost constant densities within $180 \mathrm{~km}$ and $240 \mathrm{~km}$ altitude, as was the case in the two previous figures. Note that $\mathrm{N}$ density is quite constant, as atomic $\mathrm{N}$ is substantially formed by $\mathrm{N}_{2}$ dissociation. The latter increases with altitude and becomes important for high S\&G activities. Our 4CGM results are in good agreement with NRL-MSISE-00 for $\mathrm{O}, \mathrm{N}_{2}$ and $\mathrm{N}$ densities, but give bigger $\mathrm{O}_{2}$ density. This may be due to data pertaining to $\mathrm{O}_{2}$ dissociation and has to be further investigated.

Finally, Figure 4 illustrates variation of the species densities as a function of the altitude, in case of extremely high S \& G activities. Results from MSISE-90 are represented with dashed lines. Results from our 4 CGM are also shown (big stars). We observe that in this case, atomic oxygen is by far the most abundant species for all 


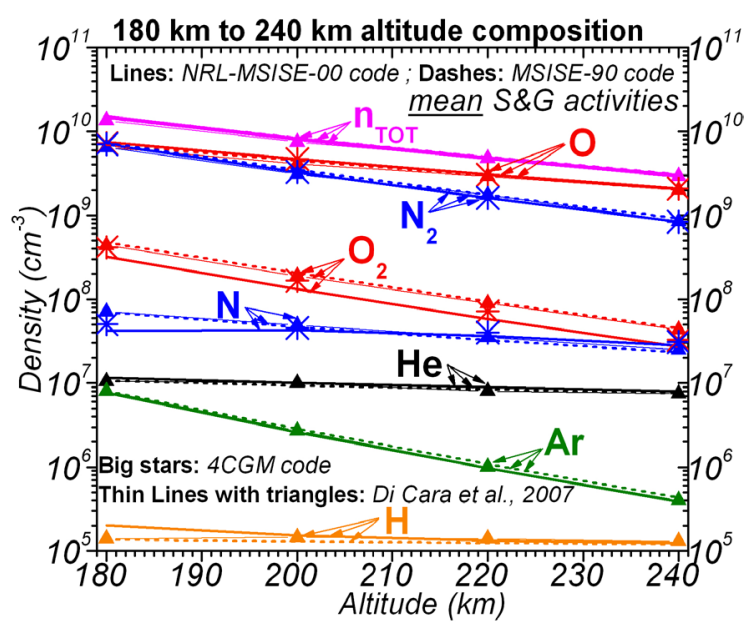

Figure 2. Comparison of species compositions for mean $\mathrm{S}$ \& G activities.

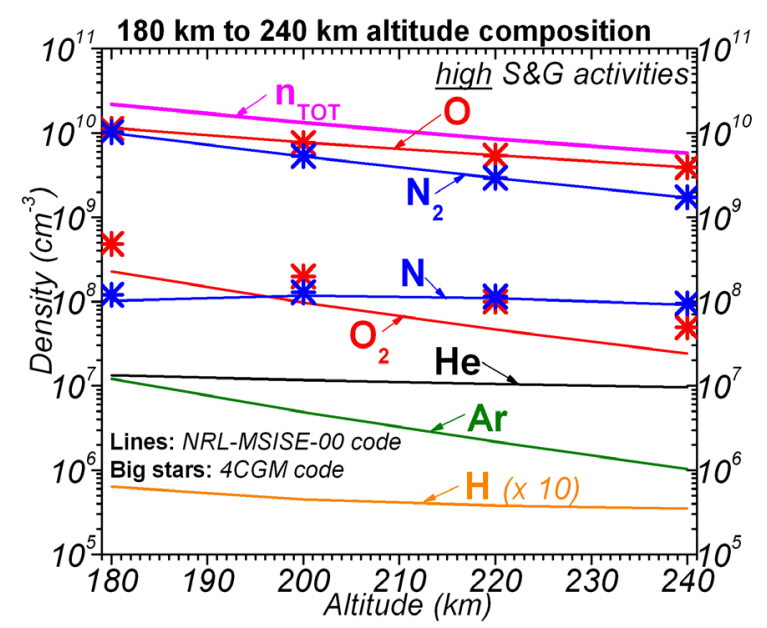

Figure 3. Comparison of species compositions for high activities.

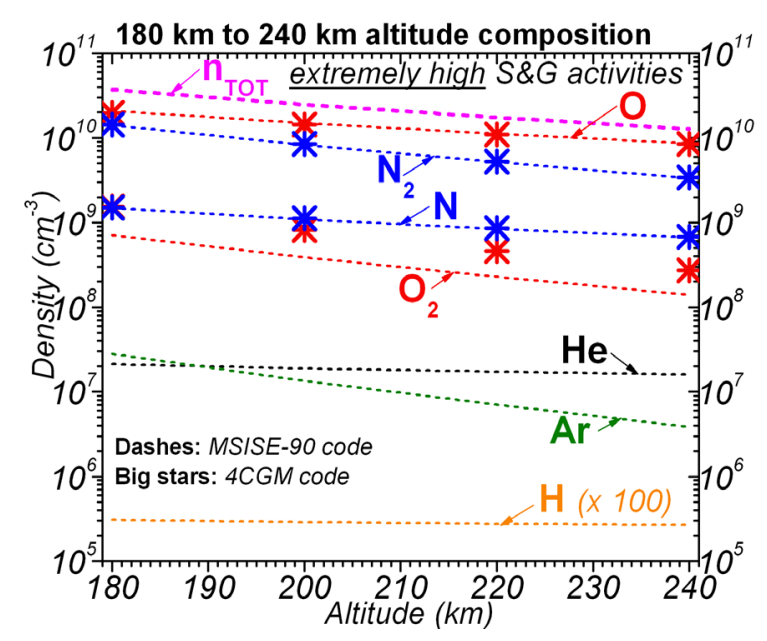

Figure 4. Comparison of species compositions for extremely high $\mathrm{S} \& \mathrm{G}$ activities. 
the altitudes. Moreover, $\mathrm{N}_{2}$ density is quite big, followed by $\mathrm{N}$ and $\mathrm{O}_{2}$ densities. The He density constitutes about $0.1 \%$ of the total density and it remains quite constant with the altitude. Ar density, although higher than this of He for $180 \mathrm{~km}$, decreases steadily with increasing altitude. Moreover, the $\mathrm{H}$ density is so low, that it was necessary to be multiplied by a factor of 100 , in order to be contained in the figure.

For extremely high S \& G activity, data from MSISE-90 have been used as input for the 4CGM calculations. We see that our 4CGM results are in good agreement with MSISE-90 for $\mathrm{O}, \mathrm{N}_{2}$ and $\mathrm{N}$ densities, as was somehow expected. However, as previously, the $\mathrm{O}_{2}$ density calculated with 4 CGM is quite higher than this of MSISE-90.

\section{Global Model Support for "Air-Breathing” Technology}

As was illustrated in the provided figures, the 4CGM considering the four main components present is able to characterize the main variations of the atmosphere composition. This includes only $\mathrm{O}, \mathrm{N}_{2}, \mathrm{~N}$ and $\mathrm{O}_{2}$ species as main components. It is also possible to add $\mathrm{H}$, He and Ar species, to obtain a 7 CGM code. Comparison of results of 7CGM versus 4CGM will be made elsewhere. By adding Ar species to the four original ones, we developed the 5CArGM code, which is of interest for $\mathrm{O}$ beam and electric thrusters characterization in LEO conditions laboratory simulations [22]. We remind that 4CGM and 5CArGM models give also the ion densities for the four/five initial species, and notably the prevailing oxygen ion one. This subject is addressed in [22].

It is important to point out that for the very low total pressures (from $9.1 \times 10^{-5} \mathrm{mTorr}$ to $5.1 \times 10^{-3} \mathrm{mTorr}$ ) expected in the $180 \mathrm{~km}$ to $240 \mathrm{~km}$ altitudes region, when the absorbed power is sufficiently low (say $10 \mathrm{~W}$ ), our results are consistent with those given by [7] [10] [11]. Our codes extend to four/five the initial components previously considered for gaseous mixtures, which were meant to address global modeling of $\mathrm{N}_{2} \mathrm{O}$, air and $\mathrm{N}_{2}$ discharges.

Detailed structure of each of the main initial compounds of atmospheric mixtures in altitudes of about $200 \mathrm{~km}$, which is taken into consideration in the present GM, allows for evaluation of the mixture radiative properties. The latter strongly depend on the absorbed power. Their calculation is necessary for diagnostics based on Optical Emission Spectroscopy (OES). In so doing, comparison of theoretical spectra with experimental ones is mandatory [20] [21].

In fact, GM constitutes a multi-physics code, which was used here for the atmosphere assessment. It can also be used for studying the propellant containment vessel and the thruster functioning and as a support of the necessary diagnostics of it.

\section{Conclusion}

We provide four figures illustrating a summary description of AtR in about $200 \mathrm{~km}$ altitude. Differences observed within available data sources become occasionally considerable. For LEO technology needs, we recommend to use results from JB2008 for total mass density. These have not been included in ECSS-04C probably because they were not made available in time. For temperature of neutrals and density of species, we propose to use results of NRL-MSISE-00 whenever exist, represented by plain lines in Figures 1-3 and results of MSISE-90 when no other data are available. Results obtained by our 4 CGM code, simplifying the situation by taking into consideration only the main four species present, are shown to be very satisfactory. In view of the obtained very satisfactory comparison of 4CGM code results to those provided by the literature we consider this code as validated for LEO applications. This allows using of our model in any case of atmospheric studies, notably within the $180 \mathrm{~km}$ - $240 \mathrm{~km}$ altitude. 4CGM code results pertaining to these altitudes will be presented and commented elsewhere [21].

\section{Acknowledgements}

Ch. Berenguer and K. Katsonis thank ESA/ESTEC/TEC-MPE for its support.

\section{References}

[1] Doornbos, E. (2012) Thermospheric Density and Wind Determination from Satellite Dynamics. Springer Theses. Springer-Verlag, Berlin Heidelberg. http://dx.doi.org/10.1007/978-3-642-25129-0

[2] Bowman, B.R., Tobiska, W.K., Marcos, F.A. and Valladares, C. (2008) The JB2006 Empirical Thermospheric Density 
Model. J. Atmos. Sol. Terr. Phys., 70, 774. http://dx.doi.org/10.1016/j.jastp.2007.10.002

[3] Bowman, B.R., Tobiska, W.K., Marcos, F.A., Huang, C.Y., Lin, C.S. and Burke, W.J. (2008) A New Empirical Thermospheric Density Model JB2008 Using New Solar and Geomagnetic Indices. AIAA/AAS Astrodynamics Specialist Conference and Exhibit, Honolulu Hawaii, August 2008, 18, AIAA 2008-6438.

[4] Bruinsma, S., Thuillier, G. and Barlier, F. (2003) The DTM-2000 Empirical Thermosphere Model with New Data Assimilation and Constraints at Lower Boundary Accuracy and Properties. J. Atmos. Sol. Terr. Phys., 65, 1053. http://dx.doi.org/10.1016/S1364-6826(03)00137-8

[5] Bruinsma, L.S., Sanchez-Ortiz, N., Olmedo, E. and Guijarro, N. (2012) Evaluation of the DTM-2009 Thermosphere Model for Benchmarking Purposes. J. Space Weather Space Clim., 2, A04. http://dx.doi.org/10.1051/swsc/2012005

[6] Hedin, A.E. (1991) Extension of the MSIS Thermospheric Model into the Middle and Lower Atmosphere. J. Geophys. Res., 96, 1159. http://dx.doi.org/10.1029/90JA02125

[7] (2000) European Cooperation for Space Standardization, Space Engineering, Space Environment, ECSS-E-ST-10-04A, ESA-ESTEC.

[8] Di Cara, D., Gonzalez del Amo, J., et al. (2007) Ram Electric Propulsion for Low Earth Orbit Operation: An ESA study. 30th IEPC Conference, Florence, September 2007, IEPC-2007-162.

[9] Picone, J.M., Hedin, A.E., Drob, D.P. and Aikin, A.C. (2002) NRL-MSISE-00 Empirical Model of the Atmosphere: Statistical Comparisons and Scientific Issues. J. Geophys. Res., 107, 1468. http://dx.doi.org/10.1029/2002JA009430

[10] (2008) European Cooperation for Space Standardization, Space Engineering, Space Environment, ESA-ESTEC, ECSS-E-ST-10-04C.

[11] (2011) ISO/DIS 14222, Space Environment (Natural and Artificial)_Earth Upper Atmosphere. ISO, Geneva.

[12] Shabshelowitz, A. (2013) Study of RF Plasma Technology Applied to Air-Breathing Electric Propulsion. PhD Thesis, University of Michigan, MI.

[13] Doornbos, E., Klinkrad, H., Scharroo, R. and Visser, P. (2007) Thermosphere Density Calibration in the Orbit Determination of ERS-2 and Envisat. Proc. Envisat Symposium, Montreux, April 2007, ESA SP-636.

[14] Jackson, D. (2013) Statement of Guidance on Space Weather Observations-Update Resulting of Recent Requirements for Radiation Dose Rate and Thermosphere Observations. World Meteorological Organization, Geneva.

[15] Doornbos, E. (2004) Calibrated High Accuracy Satellite Drag Model, ESOC Contract 16643/02/D/HK(SC) Final Report, Faculty of Aerospace Engineering Delft University of Technology, Delft.

[16] Doornbos, E. (2006) NRTDM Final Report—Near Real-Time Density Model (NRTDM)—ESOC Contract 18576/04/ D/HK(SC). Delft Institute for Earth-Oriented Space Research.

[17] Doornbos, E., Forster, M., Fritsche, B., Van Helleputte, T., Van den Ijssel, J., Koppenwallner, G., Luhr, H., Rees, D. and Visser, P. (2009) ESTEC Contract 21022/07/NL/HE, Air Density Models Derived from Multi-Satellite Drag Observations-Final Report, DEOS/TU Delft Scientific Report 01/2009, TU Delft.

[18] Katsonis, K. and Berenguer, Ch. (2013) Global Modeling of $\mathrm{N}_{2} \mathrm{O}$, Air and $\mathrm{N}_{2}$ Discharges and Applications. Lambert Academic Publishing, Germany.

[19] Katsonis, K. and Berenguer, Ch. (2014) Properties of the Atmospheric Mixtures Prevailing around $200 \mathrm{~km}$ Altitude in Conditions of Low Absorbed Power and Pressure. ESA 6th RHTG Workshop, St. Andrews, November 2014.

[20] Katsonis, K., Berenguer, Ch. and Gonzalez del Amo, J. (2015) Characterization of Air Breathing Plasma Thrusters Fuelled by Atmospheric Mixtures Encountered in Earth Atmosphere at an Altitude of About $200 \mathrm{~km}$. 34th IEPC Conference, Kobe, July 2015, IEPC-2015-268.

[21] Katsonis, K. and Berenguer, Ch. Study of the Properties of the Atmospheric Mixtures Prevailing around 200 km Altitude in Conditions of Low Pressure and Absorbed Power on the Basis of 4CGM and 5CArGM Codes, in prep.

[22] Stavrinidis, C., Gonzalez del Amo, J., Berenguer, Ch. and Katsonis, K. (2015) Diagnostics of Air-Breathing Electric Thrusters. CASE 2015 Conference, Suzhou, October 2015. 